\title{
New combinations and lectotype fixations for Dolichocodia Townsend, 1908 (Diptera, Tachinidae) with the first species key
}

\author{
Marcelo Domingos de Santis ${ }^{1^{*}}$ (D) \\ ${ }^{1}$ Universidade de São Paulo, Instituto de Biociências, Departamento de Zoologia, São Paulo, SP, Brasil. \\ urn:lsid:zoobank. org:pub:867B4BA6-9E1E-4967-A96C-ABAEE3AC6D62
}

\section{A R T I C L E I N F O}

\section{Article history:}

Received 23 August 2020

Accepted 10 September 2020

Available online 12 October 2020

Associate Editor: Marcia Couri

\begin{abstract}
A B S T R A C T
The genus Dolichocodia Townsend, 1908 has a New World distribution with four described species: D. bivittata (Coquillett, 1902), D. erratilis Reinhard, 1958, D. furacis Reinhard, 1958 and D. rava (van der Wulp, 1891). Two new combinations are suggested for this genus: D. errans (Curran, 1927) comb. nov., and D. praeusta (van der Wulp, 1891) comb. nov. Redescriptions and lectotype designations for $D$. rava and $D$. praeusta are given. An identification key to Dolichocodia species is presented. Dolichocodia rava, described from Mexico, is newly recorded from United States.
\end{abstract}

\section{Keywords:}

Dexiinae

Neotropical region

New combination

Taxonomy

\section{Introduction}

Dolichocodia Townsend, 1908 is a poorly known New World genus that included, prior to this study, four species: D. bivittata (Coquillett, 1902 ) and $D$. furacis Reinhard, 1958 from USA and D. erratilis Reinhard, 1958 and D. rava (Wulp, 1891) from Mexico (O'Hara et al., 2020). After the description of the two new species by Reinhard (1958), these species mainly appeared in catalogs (Guimarães, 1971; O'Hara \& Wood, 2004) and lists (O'Hara et al. 2020), without any keys to species or new information regarding its species.

Townsend (1938) treated the genus within the Prosenini, and this placement was kept by Guimarães (1971). However, in the last catalog of Nearctic Tachinidae, O'Hara \& Wood (2004) considered a broad definition of Dexiini, in which some tribes of Townsend were included under its name (e.g., Prosenini, Theresiini as junior synonyms). Thus, this genus is placed in Dexiini (Dexiinae) and this classification was kept in subsequently works. This tribe is a large and morphologically diverse group, with its larvae usually parasitizing Coleoptera or Lepidoptera larvae (Cerretti et al., 2014). In the first cladistics analysis of the family (Cerretti et al., 2014), Dexiini were recovered as monophyletic. Subsequently, Stireman et al. (2019) confirmed the monophyly of Dexiini. The genus Dolichocodia has not been comparatively studied, in

\footnotetext{
* Corresponding author.

E-mail: mrclsantis@gmail.com (M.D.Santis).
}

addition to not being included in any phylogenetic analysis, with other genera of Dexiini, and an updated generic diagnose is not available.

Herein, a taxonomic update for Dolichocodia is developed based on specimens and type material deposited at NHM-UK, in addition to the examined photographs available online from CNC. A generic diagnosis for this genus is given with the following new combinations: D. errans (Curran, 1927) comb nov., formerly in Prorhynchops Brauer \& Bergenstamm, 1891 and D. praeusta (van der Wulp, 1891) comb nov., originally described in Rhynchodexia (incorrect subsequent spelling of Rhynchionodexia Bigot, 1885 (Townsend, 1892), a genus with all of its former species placed in Ptilodexia Brauer \& Bergenstamm, 1889 or Senostoma Macquart, 1847 (O'Hara et al., 2020), but placed as Ptilodexia by Guimarães (1971). In the present paper, redescriptions and lectotype designations, based on the type material examined, are given for $D$. praeusta and $D$. rava. The lectotype designation was made in accordance to the purpose of fixating the identity of the name to the respective name-bearing specimen herein designated, to clarify any taxonomic doubt involving that name. A diagnosis for Dolichocodia and a key for its species is included.

\section{Material and methods}

The examined material is deposited at Natural History Museum, London, UK (NHM-UK) and Canadian National Collection of Insects, Ottawa, 
Canada (CNC). Additional depositories cited in the text: Smithsonian National Museum of Natural History, Washington, D.C., USA (USNM) and American Museum of Natural History, New York, USA (AMNH). The label data are presented within quotation marks for each label, with forward slashes indicating line breaks and semicolons separating different labels. Comments about labels, additional information and corrections are given in square brackets. Morphological terminology follows Cumming \& Wood (2017).

Photographs of the pinned specimens were taken using a Canon EOS 5Dsr and the Helicon Remote 3.9.10. The images were subsequently stacked (merging different focal planes into one image) with the software Helicon Focus 7.5.8.

Taxonomy

\section{Genus Dolichocodia Townsend, 1908}

Dolichocodia Townsend, 1908: 59. Type species: Myocera bivittata Coquillett, 1902, by original designation.

References. Coquillett (1910: 535, type species); Townsend (1936: 131, diagnosis of adults and immatures of Prosenini, including Dolichocodia); Townsend (1938: 327, redescription); Sabrosky \& Arnaud (1965: 986, catalog); Guimarães (1971: 29, catalog); Wood (1987: 1248, key to Nearctic Tachinidae); O'Hara \& Wood (2004: 25, catalog); Wood \& Zumbado (2010: 1381, key to Central American Tachinidae; 1403, comments about distribution and synonymy); Evenhuis et al.(2015: 91, catalog of Townsend's genera); O'Hara \& Henderson (2020: 25, world checklist of tachinid genera); O'Hara et al. (2020: 44, world checklist of tachinid species).

Included species:

D. bivittata (Coquillett, 1902: 121). (Myocera). Holotype male: USA, New Mexico, White Mountains, North Fork of Rio Ruidoso, 8200 feet (USNM, type not examined).

D. errans(Curran, 1927: 13). (Prorhynchops). Holotype male: Puerto Rico, Manati (AMNH, type not examined). Comb. nov.
D. erratilis Reinhard, 1958: 278. Holotype male: Mexico, Teotihuacán (CNC, examined by photographs; available on-line: https://cnc.agr. gc.ca/taxonomy/Specimen.php?id=420551).

D. furacis Reinhard, 1958: 277. Holotype male: USA, Texas, Hidalgo County (CNC, examined by photographs; available on-line: https://cnc. agr.gc.ca/taxonomy/Specimen.php?id=1933388).

D. praeusta (van der Wulp, 1891: 235). (Rhynchodexia). Two male syntypes: Mexico, Ciudad de Durango (NHM-UK, types examined). Comb. nov.

D. rava (van der Wulp, 1891: 237). ( Myocera). Four female syntypes: Mexico, Omilteme, Guerrero and Ciudad de Durango (NHM-UK, types examined).

Note. The identification of Neotropical material requires crosschecking among existing identification keys and other resources, often prepared for other regions (e.g., Wood \& Zumbado, 2010) to reach an approximation of a particular group to which a taxon may belong. Essentially, this is due to the excessive number of monotypic genera and the lack of a unique and workable identification key for supraspecific (and infraspecific) levels. Furthermore, to this date, many Neotropical Dexiini can only be identified through keys and redescriptions given by Charles Townsend in his Manual of Myiology, a 12-volume series on the "Oestromuscaria" published between 1934-1942. In this work, he produced most of the classification system for the Neotropical Region that is considered incomprehensible and confusing (Mesnil, 1980) or unmanageable and artificial (O'Hara, 2013). Therefore, as many Neotropical taxa of Dexiini still lacks a proper diagnose and keys, the limitation imposed by this scenario restricted the efforts to compare Dolichocodia with these others poorly known taxa in order to better recognize this genus.

Diagnosis. Dolichocodia differs from other Neotropical genera of Dexiini, especially to the closed resembled genera Leptodexia Townsend, 1919; Mochlosoma Brauer \& Bergenstamm, 1889; Prophorostoma Townsend, 1927, Prorhynchops Brauer \& Bergenstamm, 1891 and Ptilodexia Brauer \& Bergenstamm, 1889, mainly by the combination of the following traits: Eye bare. Parafacial with setulae (Figure 1B and 2B). Long plumose arista. Facial carina well developed and broad, blunt, and separating the antennae (Figure 2B). Lower facial margin protruding,
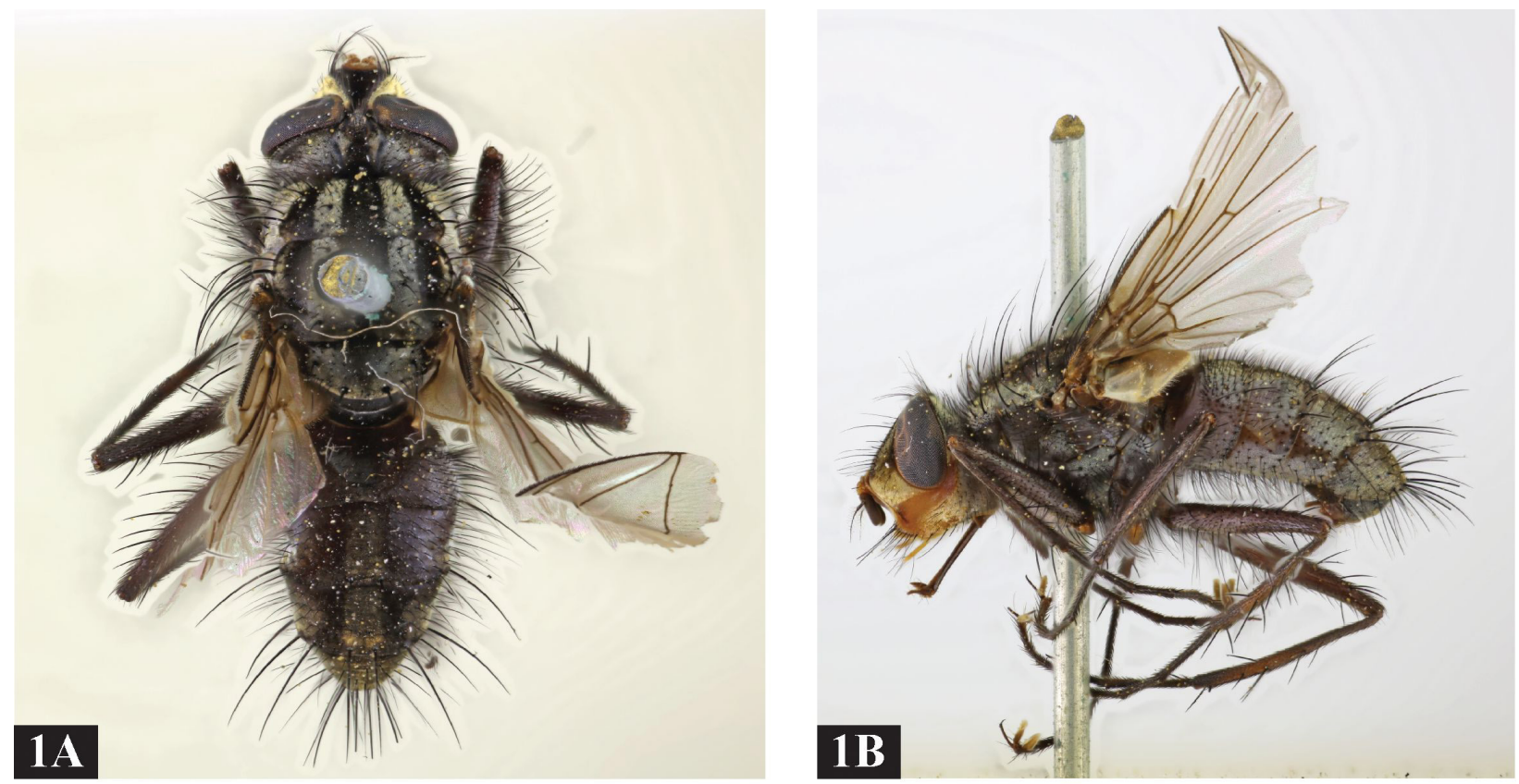

Figure 1 Dolichocodia bivittata (Coquillett), male from USA, New Mexico (NHM-UK). A. Dorsal habitus. B. Lateral habitus. 

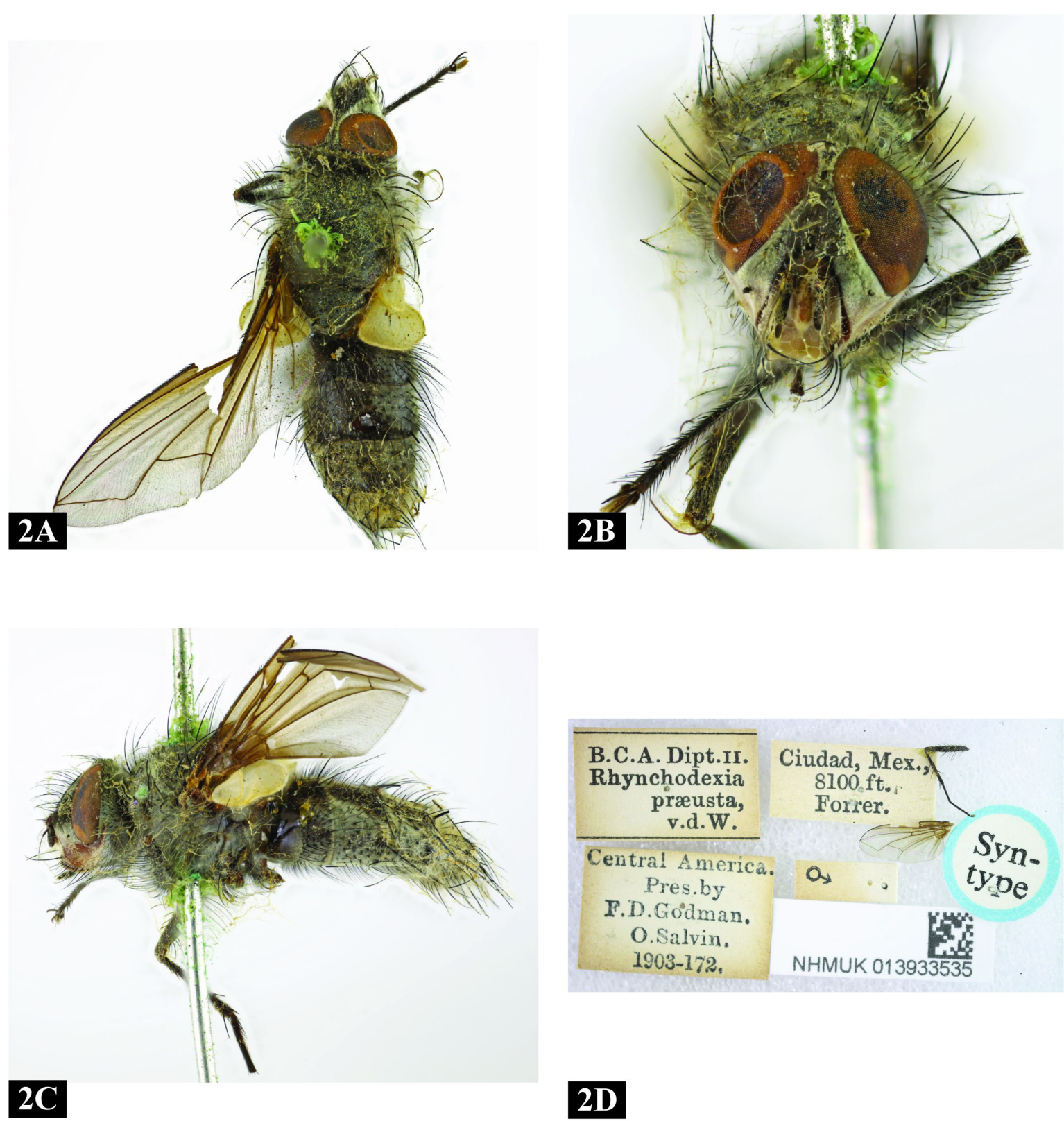

Figure 2 Dolichocodia praeusta (Wulp) comb. nov. (lectotype male). A. Dorsal habitus. B. Head, frontal view. C. Lateral habitus. D. Labels.

visible in profile. Prementum 1.0 to $1.3 \mathrm{X}$ the head height. Prosternum bare. Postpronotal lobe with 3 setae. Thorax with presutural region grayish-silver pruinose. Katepisternum with 2-3 setae. Infrasquamal setulae absent. Wing hyaline. Abdomen grayish-silver pruinose to yellowish, without discal setae (Figure 1B and 3C).

\section{Key to species of Dolichocodia}

1 - Head golden yellow pruinose (Figure 1B); thorax with 3 broad brownish black vittae (Figure 1A) D. bivittata

Head brownish black with silvery pruinosity; thorax with 5 narrow brownish black vittae

2 - Pedicel yellow to yellowish tawny, costal spine present ......... 3

- Pedicel black to reddish black; costal spine absent 4

3 - Width of parafacial measured between inner margin of compound eye and antennal insertion is $0.5 \mathrm{X}$ gena width (Figure $3 \mathrm{C}$ ); light yellow palpus; abdomen silver pruinose, but $1 / 5$ brownish black on posterior margin of tergites 3 to 5 D. rava

Width of parafacial measured between inner margin of compound eye and antennal insertion is $0.8 \mathrm{X}$ gena width (Figure $2 \mathrm{C}$ ); brownish black palpus; abdomen silver pruinose including posterior margin of all tergites D. praeusta comb. nov.

4 - Two katerspisternal setae; cell $r_{4+5}$ petiolate ... D. errans comb. nov.

- Three katerspisternal setae, cell $r_{4+5}$ separated at wing margin (Figure 2A)

5 - Setulae on parafacial long, as long as genal setae; abdomen yellowish pruinose D. erratilis

- Setulae on parafacial short, shorter than genal setae; abdomen silvery pruinose. D. furacis

On the transference of Prorhynchops errans Curran, 1927 to Dolichocodia

Wood \& Zumbado (2010) considered Dolichocodia with six species, two more than already formally considered in the genus, i.e., D. bivittata, 
D. erratilis, D. furacis and D. rava (O'Hara et al., 2020). They (Wood \& Zumbado 2010: 1403) further noted: "The Costa Rican fauna consists of four morphospecies, of which one, D. pretiosa Curran [sic], was previously placed in the genus Prorhynchops Brauer \& Bergenstamm." This statement was in error; " $D$. pretiosa" is correctly listed as Leptodexia pretiosa (Curran, 1934) by O'Hara et al. (2020), as previously treated by Guimarães (1971). Leptodexia pretiosa does not present a facial carina and the parafacial is bare (Curran, 1934), thus it is clear that this species does not belong to Dolichocodia.

Prorhynchops, as quoted by Wood \&Zumbado (2010), is a Neotropical genus that presents, until the taxonomic work developed herein, two species: P. errans Curran, 1927 and P. bilimeki Brauer \& Bergenstamm, 1891 (typespecies). Prorhynchops bilimeki was redescribed by Aldrich (1924) based on the female holotype, and he recognized the male ( 2 specimens) of this species. In addition, at the collection of Diptera of NHM-UK, I was able to study one of these males that Aldrich (1924) based his description from Hidalgo, Mexico. Thus, P. bilimeki shares with Dolichocodia the presence of a facial carina, prementum as long as head height and parafacial with setulae. However, $P$. bilimeki presents a pair of discal setae on tergite 3 and 4; traits not shared with the other species of Dolichocodia. On the other hand, $P$. errans shares with $P$. bilimeki a facial carina, prementum $1.3 \mathrm{X}$ the head height and parafacial with setulae. Nevertheless, this species does not present discal setae on abdomen, hence, $P$. errans agrees fully with the generic diagnosis of Dolichocodia given above, and it is better placed as a species of Dolichocodia, D. errans comb. nov. Indeed, Curran (1934) changed his views on the generic placement of P. errans as he highlighted that the absence of discal setae on abdomen was evidence against placing it as Prorhynchops. Moreover, D. errans shares the following additional traits with other species of Dolichocodia: long plumose arista, lower facial margin protruding, visible in profile, postpronotal lobe with 3 setae, thorax with presutural region grayish pruinose, katepisternum with 2 setae and abdomen grayish pruinose. Dolichocodia errans comb. nov., as showed in the key above, can be diagnosed from other species of the genus, mainly, by presenting the wing with the cell $r_{4+5}$ petiolate.

Dolichocodia praeusta (van der Wulp, 1891) comb. nov,

(Figure $2 \mathrm{~A}-\mathrm{D}$ )

Rhynchodexia praeusta van der Wulp, 1891: 235.

Ptilodexia praeusta (van der Wulp, 1891).

References. Guimarães (1971: 33, comb. nov. as Ptilodexia); Zetina et al. (2018: 5, checklist of Tachinidae of Mexico); O'Hara et al. (2020: 71, list).

Type material examined. Lectotype male, by present designation, deposited at NHM-UK and labeled as follows: 'Syn/type'; ‘ ‘’; 'Ciudade, Mex.,/ 8100 ft,/ Forrer.'; 'B.C.A. Dipt. II/ Rynchodexia/ praeusta, / v.d.W.'; 'Central America./ Pres. By/ F. D. Godman./ O. Salvin./ 1903-172.'; and a red label written "Lectotype" was added along with a bar code (NHMUK 013933535). Specimen in bad condition, with a broken left wing, legs and the right wing are missing from specimen (mid leg and wing are glued to one of the labels).

One male paralectotype by present designation, same locality data as lectotype, and conspecific with the lectotype. A green label written "Paralectotype" was added to the specimen.

Redescription. Body length: ca. $7.5 \mathrm{~mm}$.

Coloration. Frontal vitta and ocellar triangle dark brown to black. Fronto-orbital plate brownish black, parafacial silvery pruinose, and gena tawny-yellow. Occiput with black setulae. Scape tawny yellow brown, pedicel tawny yellow. Postpedicel black. Palpus brownish black. Labella and prementum light brown. Thorax mainly silver pruinosity; scutum with four dark vittae, in presutural region the two inner vittae are thinner than the outer, in postsutural region, the inner vittae is half the length of the outer, neither reaching the scutellum. Scutellum brownish black. Wing hyaline. Calypter hyaline to light yellow. Halter yellow-tawny. Posterior spiracle tawny yellow. Legs brownish black.
Claws brown, pulvilli yellow. Abdomen silvery pruinose, but middorsal region of tergites 3 and 4 brownish black.

Head (Figures $2 \mathrm{~B}$ and $2 \mathrm{C}$ ). Frontal vitta at its widest point ca. $0.2 \mathrm{X}$ as wide as the vertex in dorsal view. Frontal vitta, in the narrowest point width subequal to ocellar triangle. Fronto-orbital plate with 9-10 pairs of proclinate setae; about the same width of frontal vitta and parafacial. Parafacial long setulose along its extension. Facial carina well developed. Postocellar setae proclinate. Width of parafacial measured between inner margin of compound eye and antennal insertion is 0.9X the width of gena. Postpedicel slender, 2.1X the combined length of scape and pedicel; longer than the dorsal, longest cilia ca. $5 \mathrm{X}$ basal width of arista. Facial ridge with two to three setulae on lower third. Lower facial margin protruding, visible in profile. Vibrissa inserted above lower facial margin. Labella well-developed. Prementum as long head height.

Thorax (Figures 2A and 2C). Acrostichals 2+3? (or two, specimens too damaged to be certain). Dorsocentral $2+$ ? (specimens too damaged to be certain). Intra-alar 1+2; intra-postalar absent. Supra-alar $1+3$. Postpronotal lobe with three setae, two forming an anterior row and one displaced posteriorly. Anepisternum with six strong setae and with one anterior setulae directed upward. Scutellum with one basal, one subapical, one apical and one discal pairs of setae. Katepisternum with 3 setae. Anepimeron with various equally short setae with one longer (about $3 \mathrm{X}$ the length of the adjacent). Notopleuron with 2 equal-sized setae. Postalar callus with 3 setae. Prosternum bare. Anatergite bare. Posterior spiracle with posterior lappet larger than anterior. Katepimeron sparsely setulouse.

Wing (Figure 2B). Base of R vein dorsally and ventrally setulose. $\mathrm{M}$ vein bent forward to $R_{4+5}$, forming an angle slightly smaller than $90^{\circ}$, and convex after bend. Costal spine present.

Legs. Fore coxa with many setae anteriorly; fore femur with dorsal and posteroventral rows of setae; fore tibia with 1 posteroventral setae on distal third, three preapicals, 1 anterodorsal, 1 posterodorsal and 1 anteroventral. Mid femur with three anteroventral and three posteroventral seta on median third, three anterodorsal on distal third, four preapicals, 2 anterodorsals and 2 posteorventral. Hind femur with six anteroventral setae on basal half and six ventral setae on basal half, preapicals, 2 anterodorsal setae; hind tibia with four posterodorsal one median third and 1 posteroventral on median third, 2 preapicals on anteroventral surface. Claws straight with the tip curved, same length as $5^{\text {th }}$ tarsomere.

Abdomen (Figs. 2B and 2C). Syntergite 1+2 excavation halfway to posterior margin. Syntergite $1+2$ with a pair of lateral margin and medina marginal setae. Tergite 3 and 4 with one median marginal seta and one lateral marginal seta. Tergite 5 one row of marginal setae.

Terminalia. Not dissected, only male lectotype and paralectotypes were available.

Female. Unknown.

Biology. Unknown.

Distribution. Mexico.

Dolichocodia rava (van der Wulp, 1891)

(Figure 3 A-D)

Myocera rava van der Wulp, 1891: 237.

Dolicochodia rava (van der Wulp, 1891).

References. Guimarães (1971: 39, as an unrecognized species of Proseninae (Dexiinae in part)); Zetina et al. (2018: 36, checklist of Tachinidae of Mexico); O'Hara et al. (2020: 71, list, placed in Dolichocodia).

Note. Omilteme, as found in Wulp (1891) is a misspelling of Omiltemi in Guerrero.

Type material examined. Lectotype female, by present designation, deposited at NHM-UK and labeled as follows: 'Syn/type'; ' + '; 'Ciudade, Mex.,/ 8100 ft,/ Forrer.; 'B.C.A. Dipt. II/ Myiocera/ rava,/ v.d.W.'; ‘Central America./ Pres. By/ F. D. Godman./ O. Salvin./ 1903-172.'; and a red label 

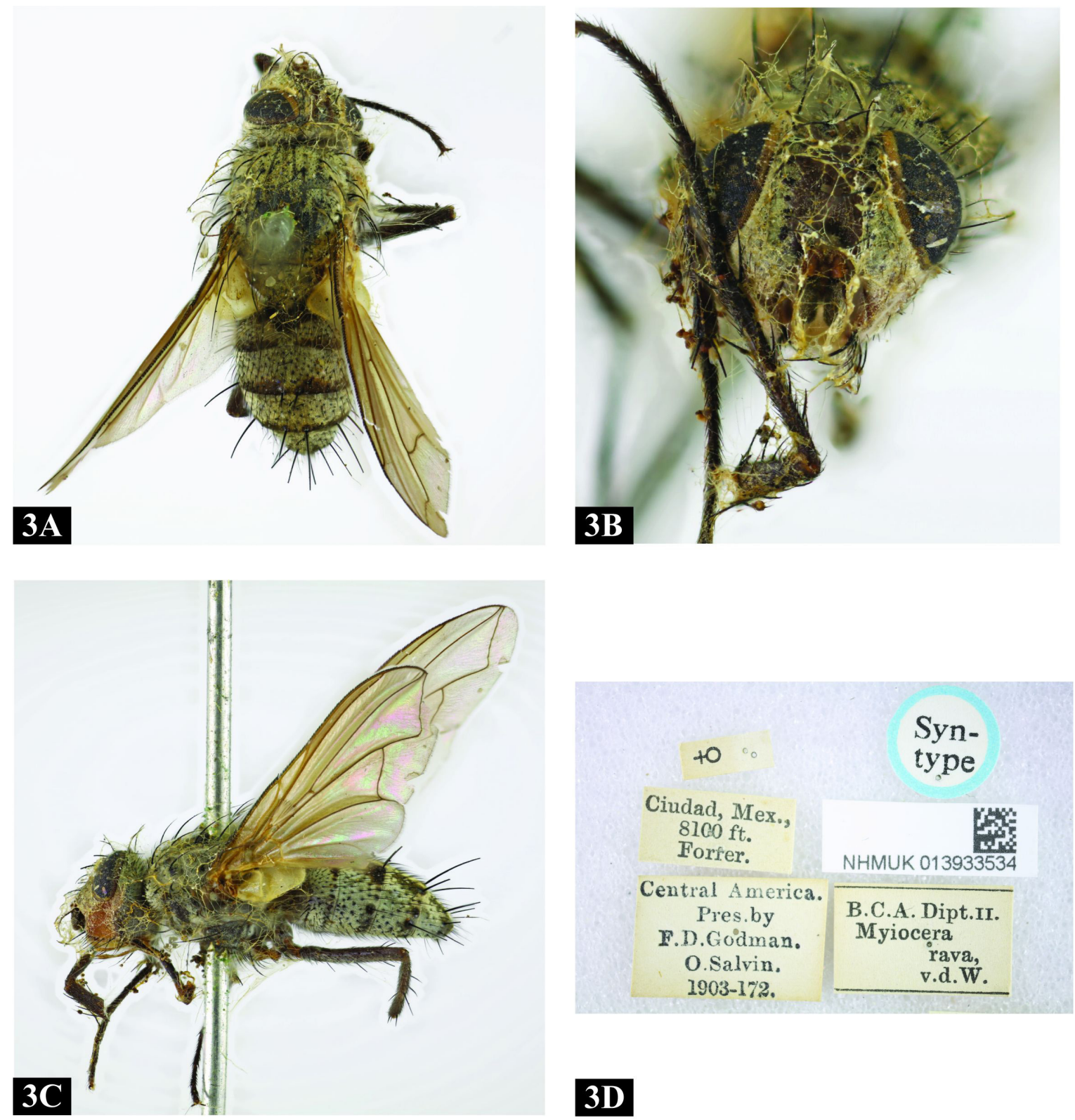

\section{D}

Figure 3 Dolichocodia rava (Wulp) (lectotype female). A. Dorsal habitus. B. Head, frontal view. C. Lateral habitus. D. Labels.

written "Lectotype" was added along with a bar code (NHMUK 013933534). Specimen in bad condition, hyphaed and damaged.

Three paralectotypes females (NHM-UK), by present designation: two with same labels and location as lectotype, and one collected in Omiltemi, Guerrero, Mexico. A green label written "Paralectotype" was added to each specimen.

Additional material examined. MEXICO. Chihuahua: Sierra Madre, Piedras Verdes, 7300 feet, (no date) 2 males, Townsend coll. (NHM-UK); USA. New Mexico, Tularosa, 6200 feet, (no date) 1 female, Townsend coll. (NHM-UK).

Redescription. Body length: ca. $7.3 \mathrm{~mm}$.

Coloration. Frontal vitta and ocellar triangle dark brown to black. Head silvery pruinose, but gena yellow. Occiput with black setulae. Scape light yellow brown, pedicel yellow. Postpedicel brownish black. Palpus light yellow. Labella and prementum light brown. Thorax mainly silver pruinosity; scutum with four dark vittae, in presutural region the two inner vittae are thinner than the outer, in postsutural region, the inner vittae is half the length of the outer, neither reaching the scutellum. Scutellum silver pruinose. Wing hyaline. Calypter hyaline to light yellow. Halter yellow-tawny. Posterior spiracle brownish black. Legs brown to tawny. Claws brown, pulvilli yellow. Abdomen with silver pruinosity, but $1 / 5$ brownish black in posterior margin of tergites 3 to 5 .

Head (Figures 3B and 3C). Frontal vitta at its widest point ca. $0.9 \mathrm{X}$ as wide as the vertex in dorsal view. Frontal vitta, in the narrowest point, $1.8 \mathrm{X}$ width than ocellar triangle. Fronto-orbital plate with 9-10 pairs of proclinate setae; about the same width of frontal vitta and parafacial. Fronto-orbital plate with 2 proclinate and 1 reclinate setae. Parafacial long setulose along its extension. Postocellar setae proclinate. Width of parafacial measured between inner margin of compound eye and antennal insertion is $0.4 \mathrm{X}$ the width of gena. Postpedicel slender, $2.2 \mathrm{X}$ the combined length of scape and pedicel; longer than the dorsal, longest cilia ca. 5X basal width of arista. Facial ridge with two to three setulae on lower third. Lower facial margin protruding, visible in profile. Vibrissa inserted above lower facial margin. Labella well-developed. Prementum as long head height.

Thorax (Figures 3A and 3C). Acrostichals 2+3? (or two, specimens too damaged to be certain). Dorsocentral 2+3. Intra-alar 1+3; intra-postalar absent. Supra-alar 1+2. Postpronotal lobe with three setae, two forming 
an anterior row and one displaced posteriorly. Anepisternum with six strong setae and with one anterior setulae directed upward. Scutellum with one basal, one subapical, one apical and one discal pairs of setae. Katepisternum with 3 setae. Anepimeron with various equally short setae with one longer (about $3 \mathrm{X}$ the length of the adjacent). Notopleuron with 2 equal-sized setae. Postalar callus with 3 setae. Prosternum bare. Anatergite bare. Posterior spiracle with posterior lappet larger than anterior. Katepimeron sparsely setulouse.

Wing (Figure 3C). Base of $\mathrm{R}$ vein dorsally and ventrally setulose. $M$ vein bent forward to $R_{4+5}$, forming an angle slightly smaller than $90^{\circ}$, and convex after bend. Costal spine present.

Legs. Fore coxa with many setae anteriorly; fore femur with dorsal and posteroventral rows of setae; fore tibia with 1 posteroventral seta on distal third, 2 preapicals, 1 anterodorsal and 1 posterodorsal. Mid femur with three anteroventral and three posteroventral seta on median third, four ventral setae on middle, mid tibia with 2 posterodorsal and 2 anteroventral setae on median third, five preapicals, 2 anterodorsals and three posteroventral. Hind femur with six anteroventral setae on basal half and six ventral setae on basal half; hind tibia with four posterodorsal one median third and 1 posteroventral on median third, 2 preapicals on anteroventral surface. Claws straight with the tip curved, same length as $5^{\text {th }}$ tarsomere.

Abdomen (Figures 3B and 3C). Syntergite 1+2 excavation halfway to posterior margin. Syntergite $1+2$ with a pair of lateral margin setae. Tergite 3 and 4 with one median marginal seta and one lateral marginal seta. Tergite 5 one row of marginal setae.

Terminalia. Not dissected.

Male. Differs from female as follows: Holoptic. Without orbital setae. Frontal orbital plate brownish black. Abdominal tergites silvery pruinose, light brown on posterodorsal view.

Biology. Unknown.

Distribution. Mexico and USA (new record).

Note. The original description cited six female syntypes. However, only four female syntypes were found in NHM-UK. Thus, the two other syntypes are, presumably, regarded as lost or destroyed.

\section{Acknowledgments}

I would like to thank the Institute of Biosciences of the University of São Paulo and Silvio Nihei (USP) for the logistical support. I am indebted to Nigel Wyatt (NHM-UK) for facilities and kind assistance during my visit, and for kindly allowing me to use the image capturing system of the museum for taking photographs. Thanks to Coordenação de Aperfeiçoamento de Pessoal de Nível Superior for a doctoral scholarship (process number 88882.333078/2019-01). Finally, James O'Hara and an anonymous referee are thanked for their comments that have greatly improved the manuscript.

\section{Conflicts of interest}

The author declares no conflicts of interest.

\section{References}

Cerretti, P., O’Hara, J. E., Wood, D. M., Shima, H., Inclan, D. J., Stireman III, J. O., 2014. Signal through the noise? Phylogeny of the Tachinidae (Diptera) as inferred from morphological evidence. Syst. Entomol. 39, 335-353.

Coquillett, D. W., 1902. New Diptera from North America. Proc. U. S. Natl. Mus. 25 (1280), 83-126.

Coquillett, D. W., 1910. The type-species of the North American genera of Diptera. Proc. U. S. Natl. Mus. 1719, 499-647.
Cumming, J. M., Wood, D. M., 2017. Adult morphology and terminology. In: Kirk-Spriggs, A.H. \& Sinclair, B.J. (Eds.), Manual of Afrotropical Diptera. Vol. 1. South African National Biodiversity Institute Graphics \& Editing, Pretoria, pp. 89-133.

Curran, C. H., 1927. New West Indian Tachinidae. Am. Mus. Novit. 260, 1-15.

Curran, C. H., 1934. The families and genera of North American Diptera. Ballou Press, New York.

Evenhuis, N. L., Pont, A. C., Whitmore, D., 2015. Nomenclatural studies toward a world list of Diptera genus-group names. Part IV: charles Henry Tyler Townsend. Zootaxa 3978 (1), 1-362.

Guimarães, J. H., 1971. Family Tachinidae (Larvaevoridae), In: Papavero, N. (Ed.), A catalogue of the Diptera of the Americas South of the United States, Vol. 104, Museu de Zoologia, Universidade de São Paulo, São Paulo, pp. 1-333.

Mesnil, L.P. 1980. Dexiinae. In: Lindner, E. (Ed.), Die Fliegen der Palaearktischen Region (Lieferung 323), E. Schweizerbart'sche Verlagsbuchhandlung, Stuttgart, Vol. 9, pp. 1-52.

O'Hara, J. E., 2013. History of tachinid classification (Diptera, Tachinidae). ZooKeys 316, 1-34.

O'Hara, J. E., Henderson, S. J., 2020. World genera of the Tachinidae (Diptera) and their regional occurrence. Version 11. p. 90. Available in: http://www.nadsdiptera.org/Tach/WorldTachs/Genera/Worldgenera. htm (accessed 06 March 2020).

O’Hara, J. E., Henderson, S., Wood, D. M., 2020. Preliminary checklist of the Tachinidae (Diptera) of the world. Version 2.1. pp. 1039 Available in: http://www.nadsdiptera.org/Tach/WorldTachs/Checklist/ Worldchecklist.html (accessed 06 March 2020).

O'Hara, J. E., Wood, D. M., 2004. Catalogue of the Tachinidae (Diptera) of America north of Mexico. Memoirs on Entomology. International $18,1-410$.

Reinhard, H. J., 1958. North American Tachinidae (Diptera). J. Kans. Entomol. Soc. 31, 277-284.

Sabrosky, C. W., Arnaud Jr, P. H., 1965. Family Tachinidae (Larvaevoridae), In: Stone, A., Sabrosky, C.W., Wirth, W.W., Foote, R.H., Coulson, J.R. (Eds.), United States Department of Agriculture, Agriculture Handbook, A catalog of the Diptera of America north of Mexico. Vol. 276, pp. 961-1108.

Stireman III, J. O., Cerretti, P., O’Hara, J. E., Blaschke, J. D., Moulton, J. K., 2019. Molecular phylogeny and evolution of world Tachinidae (Diptera). Mol. Phylogenet. Evol. 139, 106358.

Townsend, C. H. T., 1892. The North American genera of calyptrate Muscidae. Paper III. Trans. Am. Entomol. Soc. 19, 273-278.

Townsend, C. H. T., 1936. Manual of myiology in twelve parts. Part III. Oestroid classification and habits. Gymnosomatidae to Tachinidae. Privately published, Itaquaquecetuba, São Paulo.

Townsend, C. H. T., 1938. Manual of myiology in twelve parts. Part VII. Oestroid generic diagnoses and data. Gymnosomatini to Senostomatini. Privately published, Itaquaquecetuba, São Paulo.

Wood, D. M. 1987. Tachinidae, In: McAlpine, J.F., Peterson, B.V., Shewell, G.E., Teskey, H.J., Vockeroth, J.R. \& Wood, D.M. (Eds.), Manual of Nearctic Diptera. Vol. 2. Research Branch Agriculture Canada Monograph, Ottawa, pp. 1193-1269.

Wood, D. M., Zumbado, M. A., 2010. Tachinidae (tachinid flies, parasitic flies), In: Brown, B.V., Borkent, A, Cumming, J.M., Wood, D.M., Woodley, N.E., Zumbado, M.A. (Eds.), Manual of Central American Diptera. Vol. 2, NRC Research Press, Ottawa, pp. 1343-1417.

van der Wulp, F. M. 1891. Fam. Muscidae, In: Godman, F.D., Salvin, O. (Eds.), Biologia Centrali-Americana, or, contributions to the knowledge of the fauna and flora of Mexico and Central America. Zoologia. Class Insecta. Order Diptera. Vol. II. [1888-1903.] Taylor \& Francis, London, pp. 225-248.

Zetina, D. H., Romero-Napoles, J., Contreras-Ramos, A., Carrillo Sánchez, J. L., 2018. Checklist of Tachinidae (Insecta, Diptera) in Mexico. Trans. Am. Entomol. Soc. 144 (1), 1-89. 